\title{
The E-Governance (E-GOV) Information Management Models
}

\author{
Khalid A. Fakeeh, PhD \\ King Abdullaziz University \\ Jeddah, Saudi Arabia
}

\begin{abstract}
E-governance is an evolution method of governance which advocates for better governments that are participative, transparent and all-inclusive. These models of digital governments are still evolving in the developing countries. Egovernance is based on intrinsic characteristics of ICT like enabling similar access to data for everyone who is a part and parcel of the digital network platform and connecting all sources of information across the entire digital network domain. In e-governance, information is not retained in a particular node but flows uniformly to all the nodes in the entire network [2]. E-governance does not implant the ordinary procedure of data flow that enhances the uneven flow of information and therefore distorted power control in the government. E-Governance as I have said is an evolutional move for better governments which are efficient, in the implementation of some new trends in governance models. However, E-Governance is not implemented well yet since there are several barriers to its full implementation. In fact, this method of governance has not yet been learned by many people as compared to eLearning and eCommerce. Unlike this two, common e-technology, e-governance needs to be practical. One major difference between e-governance to eLearning and eCommerce is that e-Governance entails knowledge management whereas the duo involves information management. Expounding more on this, knowledge management is the administration of skills, information, intelligence, experience and innovation [3]. An e-Government founded on knowledge management system, is created upon the following pillars;
\end{abstract}

- Knowledge capturing

- Knowledge allotment

- Knowledge enhancing

- Knowledge conservation

\section{Keywords}

E-Government, IT, Models, Information Management

\section{INTRODUCTION}

As mentioned earlier, e-government is a technological government; it uses the latest models of ICT infrastructure to deliver services to its people in a more efficient manner. Traditionally, government services to the citizens were performed very poorly. For instance, people had to wait for days in queues waiting to be served by government staffs. Think of filling tax returns manually, paying bills such as water and electricity in the respective offices [2]. These methods of service delivery were very impracticable and a waste of a nation's time in the path of progress. In those days, government protocols were very complex such that before you get your problem solved by the right person, a few days would go to waste for no particular reason. These disadvantages in the analog methods of governance called for better governing and service delivery methods. Developed and industrialized countries were the first ones to test various methods of egovernance. Appropriate governance changes and some reengineering in the provision of services methods had to be done. This re-engineering is what led to the creation of egovernance models of administration. As reforms happened and different models of e-governance took shape, different countries developed their own. Therefore, e-governance models are fundamentally diverse in the developed and developing countries as a result of various initial conditions, design, expectations, and perspectives of better governance methods.

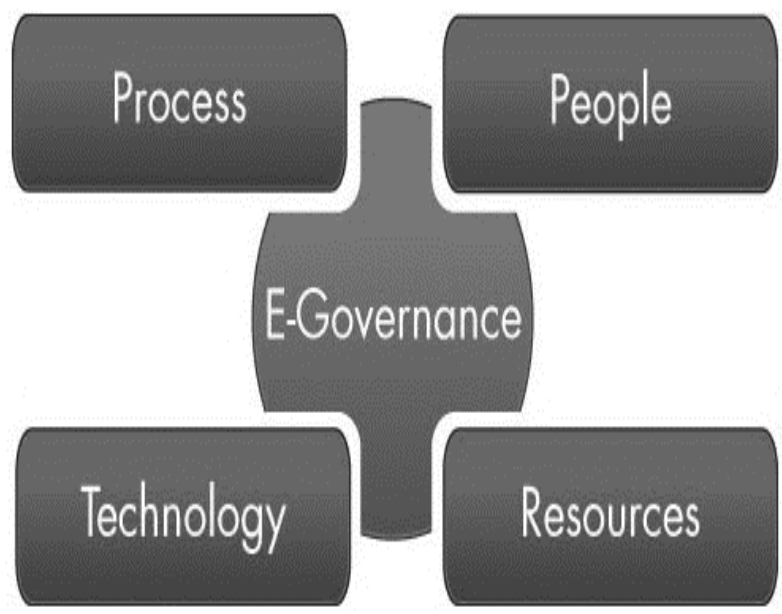

(a)

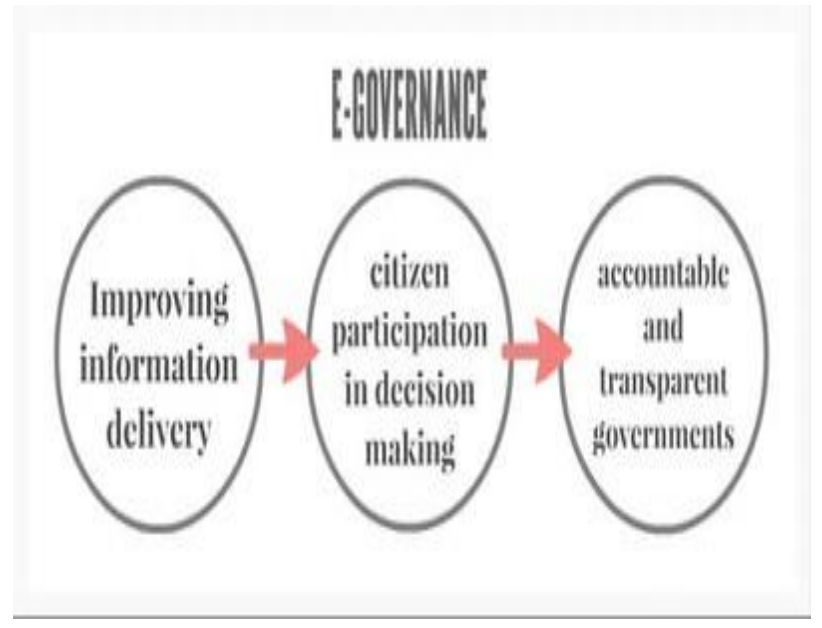

(b) 


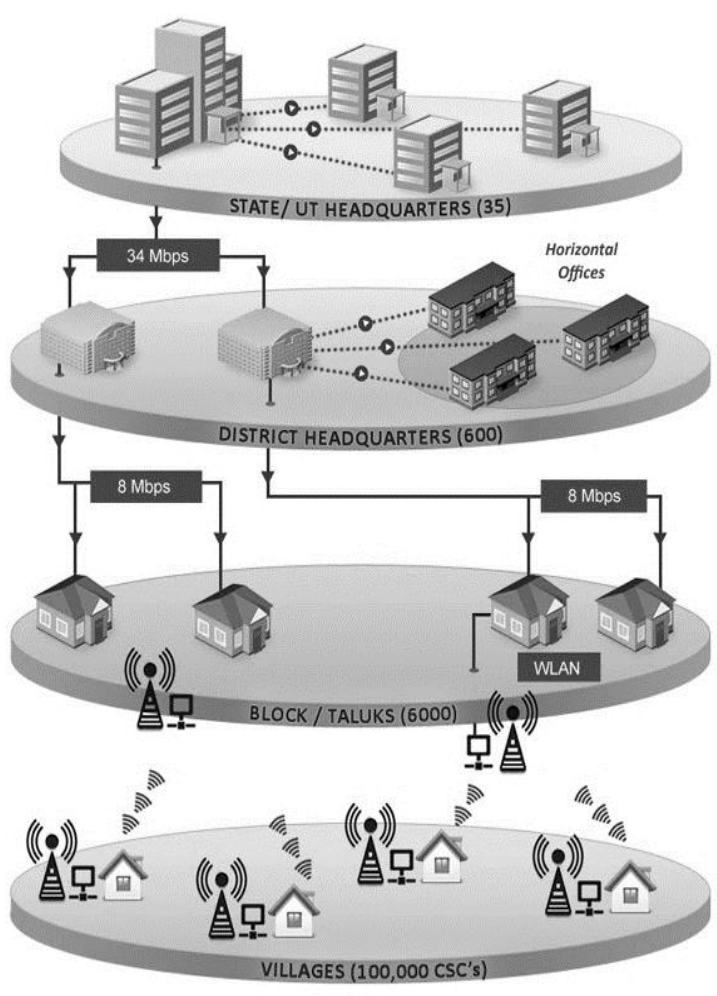

(c)

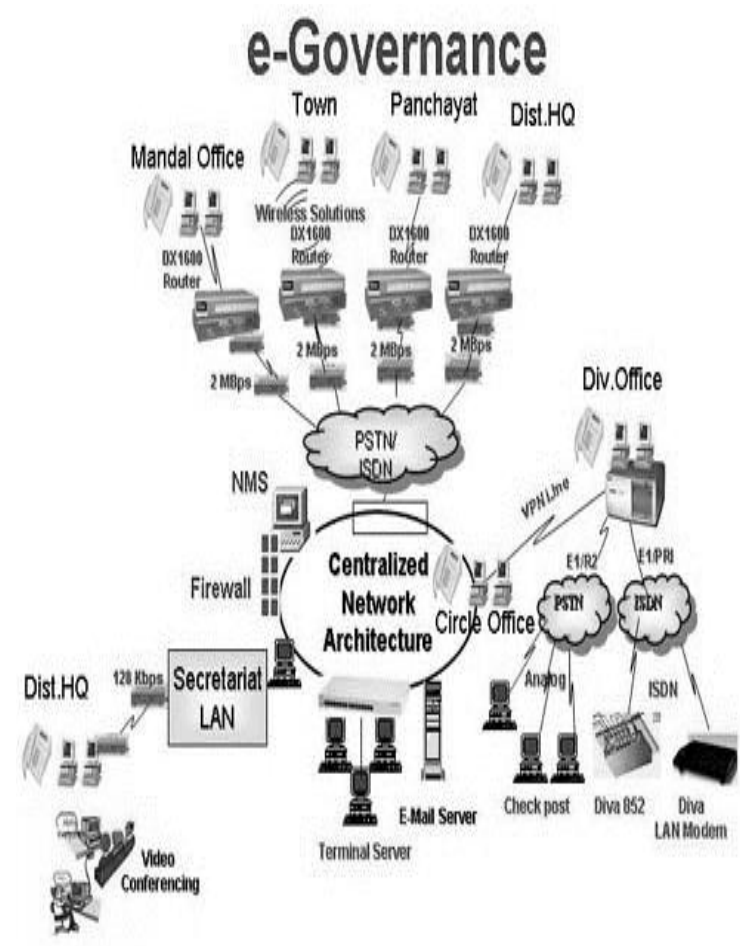

(d)

Figure 1 (a,b,c,d): E-Governance Four Pillars \& Architecture

\section{MODELS OF E-GOVERNANCE IN DEVELOPING COUNTRIES:}

1. Critical flow model

2. Comparative analysis model

3. Wider/Broadcasting dissemination model

4. Interactive service model

5. Mobilization and lobbying model

These models show some variations depending on the general local situation and the functions of governance throughout these models [5]. Various features of all e-governance models include the following;

- Standard health services and information

- Legislation and executions of laws

- Access to government officials and their offices

- Address on shared environmental challenges through the digital platform

- Warnings to the citizens in case of any predictable disaster such as earthquakes and floods

\subsection{Critical Flow Model}

A critical flow model of e-governance is a digital governance that's operates within private and public domains. This model has been able to address and access information such as:

- Violations of human rights

- Security threats

- Information on corruption both in the public and private sectors

- The green ratings of a company

\section{Critical Flow Model Critical Domain $\longrightarrow$ Targeted / Wider Domain}

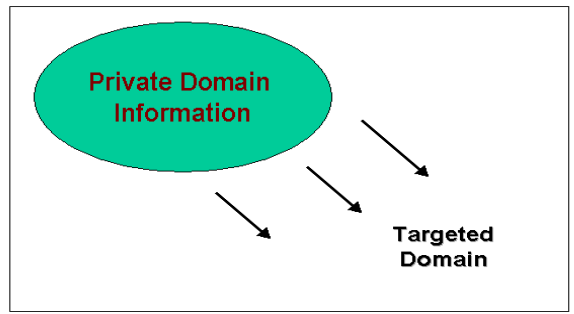

Figure 2: Critical Flow Model

\subsubsection{Principal of Operation}

The critical flow model is based on distributing key value data to the targeted people or by disseminating it to the broad public using any available convergent media or through ICT. This model requires the users to understand the importance of any data set and how to use it strategically. Also, it may involve establishing the position of users to whom the accessibility of particular data can make a significant difference in implementing good governance. The vigor of this model is the inbuilt uniqueness of ICT which makes the concept of time redundant and distance. This concept lowers cases of exploiting governments which are possible as due to the time lag between availability of data between various users. 


\subsubsection{Applications of critical flow e-} governance

a. Availing appraisal commissioned by the government to the people, research studies, and reports of inquiry

b. Availing records of human rights violation and criminal impeachment against government officials to concerned citizens and non-governmental organizations [7]

c. Facilitating information on the corruption of particular government officials or ministries to the electoral bodies or to any relevant governing council

d. making available information on the environment to the local citizens such as effluent discharge to rivers, sources of radioactive elements which are a health hazard just to mention a few

\subsubsection{Evaluation of critical flow model}

Pros

1. Critical model is based mostly on the direction of its information and its prospective users [6]. By concentrating on the important aspect of data, it the weakest feature of governance and its decisionmaking body.

2. This model informs people about particular instances of political failure and improper governance.

3. While fuelling public strife, this system puts pressure on the responsible government officials and bodies to take into consideration the concerns and the opinions of citizens while making decisions.

Cons

1. The government itself may have a limited motivation, and attitudes in sharing such important information.

2. The only way to achieve such a model is to lay its implementation responsibility to civil societies so as to have efficient watch on government actions and policies [7]

3. The model may not work properly on instances where the government bodies do not encourage public contributions and criticize all information of critical nature

4. Finally, the model will also fail where the government maintains tight control over all information and remains available to only a few top levels of the government.

\subsubsection{Successful projects based on critical flow model}

\section{India}

India Central Vigilance Committee has a website which provides access to information freely about the government servants who have been implicated in legal charges related to corruption to the citizens. In this site, people can file complaints aligned with a public servant who falls in the jurisdiction of the commission.

\section{Bangladesh}

Bangladesh Human Rights Portal: the networking of this portal actively endorse human rights changes in the political boundaries of Bangladesh. Also, the portal supports women, marginalized communities, children and citizen in resisting any social repression.

Transparency International's Corruption News

This organization runs a website called "The Daily corruption News" that reports on all corruption cases globally.

\subsection{Comparative Analysis Model}

Operation principle- though this is the least growing model of governance, it is highly effective hence the reason why it is gaining popularity gradually. This model operates with a particular purpose of exploring information from both the private and public domain and compare it with the known information hence deriving premeditated learning's and opinions. Comparative analysis model systematically assimilates fresh knowledge products and use them to manipulate, assess and campaign for change in governance actions and policies. Benchmarking must be done to compare different events of the past and the current situation, or compare two separate situations to comprehend the efficiency of an intercession [8]. The vigor of this model is in ICT which can store data in a retrievable manner and share it instantly across all networks and beyond any hierarchical or geographical barriers.

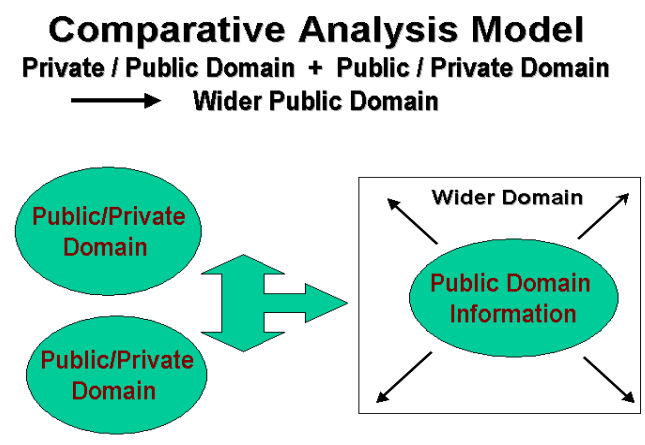

Figure 3: Comparative Analysis Model

\subsubsection{Applications of Comparative Analysis} Model

a. This model establishes the conditions of prior preference, particularly in the case of legal or judicial decision-making, and uses it to manipulate how decisions are made in the future.

b. Used in assessing the performance of a particular public servant, ministry or the government.

c. Enables making informed decisions at all government levels by empowering the background to know how and provide a justification for the future course of action

d. This model is used to gauge the efficiency of the current policies by digging up lessons from the egovernment guiding principles and measures in the past.

\subsubsection{Evaluation (Pros and Cons)}

Pros

The developing countries can use this model to their benefit as ICT unlocks access to local knowledge and global products at 
very low cost.

Organizations trusted in maintaining this digital platform may use it to track the performance of electoral candidates and share the records in their constituencies.

\section{Cons}

This model can become useless/ ineffective in the absence of vigorous civil societies welfares and little public memory

Also, the model relies on the availability of other information's for comparison and the attitude of people to examine and come up with self-explanatory or strong arguments from the analysis.

\subsubsection{Successful projects based on critical flow model}

\section{Philippines}

The Philippines have a website call vote.Ph, which is nonsectored, non-partisan online information bank. This is the reference center for Philippine elected officials on the local and the national level. This directory is used by voters to know who runs in their electoral areas and who their current representative is.

\section{India}

India, the Center for Science and Environment carries out surveys of how environmental friendly Indian industries are. This project is mainly an attempt to facilitate fair and independent examination of the relative environmental performance of various industries. It attempts to a perspective which supports accountability in industries and on the other hand encourage poor performers to compete. After evaluation, the performance of these companies is shared online and mass opinions implored in deciding the greenest industry.

\section{Global project}

Human development indicators- the UNDP report on human development index makes use of stored statistical data regarding health, literacy, national income just to mention a few as a benchmark to evaluate the performance of made in different countries regarding their organization.

\subsection{Broadcasting/Wider Dissemination Model}

Principle- this model of e-governance is based on the distribution of information which is essential for better governance. The work of the model is to reach a wider public domain through the use of ICT since this information is already in the public sphere. An informed citizen understands governance mechanism quickly and is in a position to make sober choices in exercising his responsibilities and rights. It is likely that the areas where these informed citizens are will ensure that the correct governance methods are implemented without fear or favor [8]. Broadcasting model of governance unlocks up an alternative channel for people to gain access to data and also distribute it to the local or public domain from outside sources. When this model is widely spread, it eventually corrects the situation of communication failure and gives people information related to the government so that they can come up to consensus and decide the future course of action.

\section{Broadcasting / Wider Disseminating Model \\ Public Domain $\longrightarrow$ Wider Public Domain}

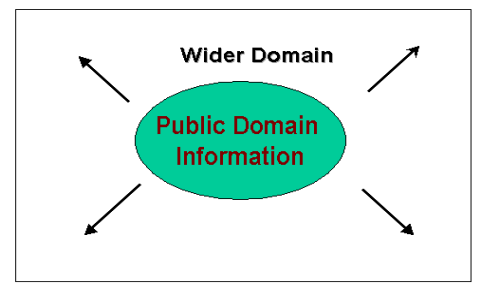

Figure 4: Broadcasting Model

\subsubsection{Applications of Wider Dissemination}

Model

- Putting into the public domain, the names, contacts and address of government officials

- Posting government legislations and laws into online platforms for easier access

- Making significant judicial statements/ judgments that are vital to citizens online

- Availing information about plans of the government such as budgets, security conditions, and expenditures online

\subsubsection{Evaluation}

Pros

If national governments aggressively adopt this model, they will effectively create an environment that enhances participation of its people in domestic matters. This model is the very first move in achieving e-governance platforms since it facilitates free flow and access to information to all parts of the society hence can be referred as the building block of digital governance [7].

Cons

This model is not useful when the government controls the information being put in the public domain. Also, the model is pointless when free flow of important content is not encouraged. Therefore, it is the sole responsibility of civil societies and government organizations to ensure that this model becomes successful.

\subsubsection{Successful projects based on the wider model of e-governance:}

\section{Brazil}

The official National E-government website provides comprehensive information about the government as well as integrates citizens to the E-government

\section{South Africa}

In South Africa, there is a network called the Chapter 2 Network which is a center to clear communication and information for social justice. This network distributes information about research and political intelligence, support campaigns and legislation scrutiny to civil society organizations involved in social justice.

Earth Negotiations Bulletin- is a network service that keeps citizens around the globe aware of international environmental negotiations, decisions, and processes. It's of primary value to 
governments and the people especially in the developing countries so as to record international decisions and take the necessary precautions.

\subsection{Interactive-Service Model / G2C2G}

Interactive-service system of government can also be referred to as Government to Citizen to Government model. This model is a consolidation of different E-governance models and allows direct participation of persons in the digital governance process. ICT is used in this model to incorporate all people within a knowledge network thus enabling interactive communication media within them.

G2C2G entirely includes the potential of ICT and use it for greater transparency and efficiency, and participation in government functions as well as saving time and cost related to the decision-making process. Citizens can access all services of the government through this model since it creates a channel in functions such as government procurements, sharing of concerns, filling of tax returns just to mention a few.

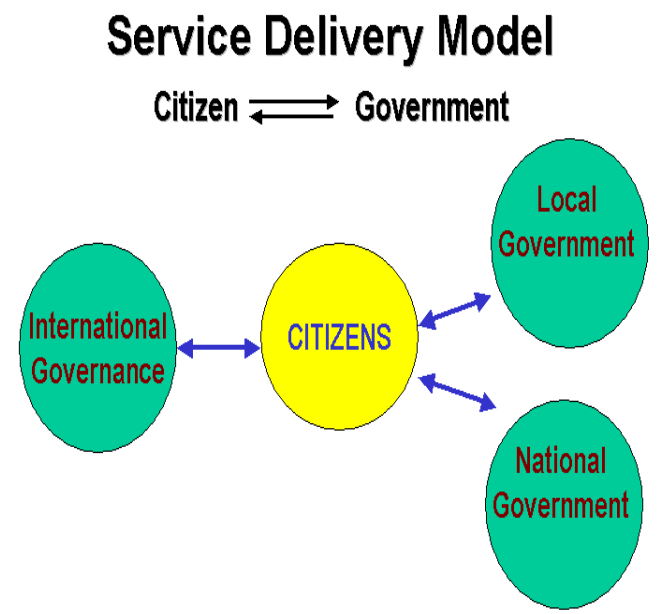

Figure 5: Interactive Service Model

\subsubsection{Applications of $G 2 C 2 G$}

a. Used in conducting electronic ballots during election of government officials

b. Filling of reports and grievances to various government bodies by the citizens

c. Establishing an all-inclusive communication channel such as online dialog and video conferencing

d. Used in carrying out opinion polls or public debates on issues affecting the everyday citizens

e. Doing governance functions in an online platform such as filing of taxes, revenue collection, and payment transfers

\subsubsection{Evaluation of $G 2 C 2 G$}

Pros

This model of governance is more applicable in the developed nations and has been projected for use in the developing countries.

Cons

The model is highly reliable to technology as compared to other models hence making it hard to copy in the developing countries which lack reliable ICT infrastructure

\subsubsection{Successful projects on Interactive Service Model}

This model of E-governance has been used in Dhar, which is a district in Pradesh. It connects rural cybercafés to cater for the everyday need of citizens. The site offers services such as online applications and registrations, copies of land maps, and public complaint redress.

\section{Philippine}

Secondly the model has been used in Philippines custom bureau which is an online system that has been developed to aide in clearance at the ports, duty payment, and delivery of orders for ships to leave the doc. This digital platform has reduced cases of the graft within government arms hence making the revenue bureau maximize revenue collection.

\subsection{Mobilization and Lobbying Model}

It is the most common model of E-governance and has always helped civil society organizations to influence global decisionmaking procedures especially in developing countries.

Mobilization model is based on strategic, the directed flow of information to strengthen action and build strong allies [9]. It takes up a proactive approach of building virtual communities which promote vigorous sharing of information and sharing of similar values. The diversity of these virtual communities is the strength of this model and the resources, and ideas brought together through virtual methods of network.

The lobbying model can effectively overcome institutional, geographical and bureaucratic barriers to shape rigorous action.

\section{Mobilisation and Lobbying Model Networking Networks for Concerted Action}

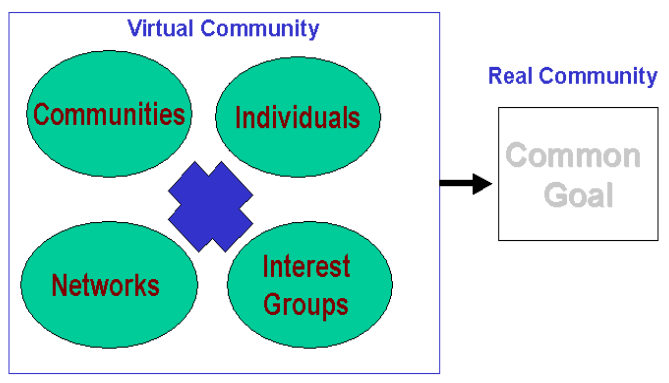

Figure 6: Mobilization\& Lobbying Model

\subsubsection{Applications Mobilization and}

\section{Lobbying Model}

a. Formation of groups that compel decision-making organizations to recognize their concerns

b. Advocating for the rights of the marginalized groups from the decision-making organs

c. Compelling for public debates on global issues and themes of any imminent conferences

d. Advocating for wider involvement in decisionmaking processes 


\subsubsection{Evaluation (Pros and Cons) Pros}

1. This model gained ground after the onset of the Seattle round of WTO which led to the formation various virtual communities that advocate the concerns of the developing nations in the WTO agreement. This was as a result of massive discussions that must have taken place over virtual networks before the summit.

2. The model increases the range of membership of individuals and communities in debates and any policy issues.

3. The model creates a limit for members to be careful or get the opinion of the global members is against them [9].

4. This model can also be used to gauge public opinions by the government, especially on particular issues.

\section{Non-internet e-government}

An e-government is always thought to be an online government; however there are lots of non internet electronic gadgets which can be used in this context. Some of these non internet devices include fax, telephone, and message texting and wireless network services. These modes of transmitting data without the need of being connected to the internet make a non-internet e-government.

\section{Merits of an e-government}

Efficiency in service delivery: delivery of services to citizens has become much more efficient as information for the ordinary man is stored or can be accessed online hence no need for him to carry too much forms such as certificates [12]

Improved services: compared to the traditional methods of giving services, e-governance has improved service delivery as there are no longer too much wastage of time in processing the data of a citizen

Enhanced accessibility of public services: one can access his/her own information at his own convenient time. You no longer need to queue for so long for the simple reason of paying your water bills. This service can be accessed and sorted within the e-governance online platform.

Transparent and accountable government agents: there are no more loop loopholes which government officials always utilized to perform illegal transactions such as corruption

\section{Demerits of e-governance}

- The cost of managing various e-governance models is expensive.

- To manage an e-government IT center is very complex.

- One of the most challenging things in a technological information platform is to maintain security of the data [12]. Once data is lost where there is no backup, then retrieving it will be expensive.

\section{CONCLUSION}

Every government, either in the developed or the developing countries should work towards achieving a digital governance model. As illustrated in this report, there are numerous advantages related to the idea of E-governance. Through this report, you can be sure that E-governance models bring adequate transformations in the on hand forms of governance as they transform the situation of citizen governance relationship and bring in a new era of influencing governance decision-making processes. E-governance models make certain that the voice of the people is reflected in the decision-making organs [12]. Democratic control is fostered over social, economic and welfare policies by civil societies and citizens. This is important for shaping responsive and good governance. The relationship between the citizens and government has been improved tremendously through the models of digital governance. Information flows freely both vertically, laterally hence covering a wider basis of civil society. Freedom of expression, therefore, gets exercised well by the citizens who are willing to be a part of the political processes. In Egovernance models, it is hard to capitalize information for any political gains at the expense of unaware citizens. Digital governance facilitates equal sharing of power among citizens, civil societies, and the opposition parties. Since methods such as direct participation, opinion casting, and participating in public debates, there is greater chance to influence civil societies and policy makers. Since the voice of the people is well heard through digital governance platforms, policy makers can involve them efficiently in policy making decisions. Government officials realize that their actions are well scrutinized by the people and civil societies hence they have to be very careful. Through E-governance, it is very hard to manipulate information hence the memory of institutions and the people is always intact.

\section{REFERENCES}

[1] "Government to Employee". Eon Technologies. Retrieved 2010-01-18.

[2] Dawes, Sharon S. "The Evolution and Continuing Challenges of E-Governance." - Dawes. Wiley Online Library, n.d.

[3] Bertot, Jaegar, and McClure, (2008). "Citizen Centered EGovernment Services: Benefits, Costs, and Research Needs". Montreal, Canada.

[4] "U.S. Department of Labor E-Government Strategic Plan". United States Department of Labor. Retrieved 2010-01-19.

[5] Garson, D.G. (2006). Public Information Technology and E-Governance. Sudbury, MA: Jones and Bartlett Publishers.

[6] Saugata, B., and Masud, R.R. (2007). Implementing EGovernance Using OECD Model(Modified) and Gartner Model (Modified) Upon Agriculture of Bangladesh. IEEE. $1-4244-1551-9 / 07$

[7] White, Jay D. (2007) Managing Information in the Public Sector. M.E. Sharpe. New York

[8] Fang, Zhiyuan. "E-government in Digital Era: Concept, Development, and Practice." International Journal of the Computer 10.2 (2002): 1-22

[9] Carter, Lemuria, and France Belanger. "Citizen Adoption of Electronic Government Initiatives. IEEE Xplore. Virginia Polytechnic Institute and State University, n.d.

[10] "On demand government". The Daily Telegraph (London). 18 November 2003. Retrieved 2010-01-19. 
International Journal of Applied Information Systems (IJAIS) - ISSN : 2249-0868

Foundation of Computer Science FCS, New York, USA

Volume 11 - No. 1, June 2016 - www.ijais.org

[11] "E-Government for Developing Countries:Opportunities and Challenges". The Electronic Journal on Information Systems in Developing Countries (EJISDC). 2004.

[12] Moon, M. J. (2002), The Evolution of E-Government among Municipalities: Rhetoric or Reality? Public Administration Review, 62: 424-433

[13] Marche, S. and McNiven, J. D. (2003), E-Government and E-Governance: The Future Isn't What It Used To Be.
CAN J ADM SCI, 20: 74-86.

[14] Mary Maureen Brown. "Electronic Government" Jack Rabin (ed.). Encyclopedia of Public Administration and Public Policy, Marcel Dekker, 2003, pp. 427-432.

[15] Bakry, S. H. "Development of e-government: a STOPE view." International Journal of Network Management. 2004, 14(5), 339-350. 